\title{
APROPRIAÇÃO DOS RESULTADOS DAS AVALIAÇÕES EXTERNAS PELOS PROFESSORES PARA A MELHORIA DA QUALIDADE DO ENSINO NAS ESCOLAS PÚBLICAS
}

\section{APPROPRIATION OF THE RESULTS OF EXTERNAL EVALUATIONS BY TEACHERS TO IMPROVE THE QUALITY OF EDUCATION IN PUBLIC SCHOOLS}

\author{
Pedro Fernando Sahium ${ }^{1}$ \\ Cláudia Valéria Magalhães ${ }^{2}$ \\ Íris Teixeira de Araújo ${ }^{3}$ \\ https://doi.org/10.29327/216986.1.1-3
}

RESUMO: A busca pela qualidade do ensino na educação básica nas escolas públicas é um desafio no país. As avaliações externas tem sido uma ferramenta recorrente na tentativa de solucionar problemas com medidas mais assertivas. O objetivo deste estudo é abordar como se dá a apropriação dos resultados das avaliações externas pelos professores da Educação Básica, com base na melhoria do ensino-aprendizagem dos alunos. $\mathrm{O}$ texto foi produzido a partir de uma pesquisa bibliográfica, de caráter exploratório e qualitativo. Abordar essa temática tem relevância porque, além de ser uma questão atual e necessária no país, é enriquecedora no contexto acadêmico. Os resultados apontam as avaliações externas, porém com pouca eficácia à melhoria da qualidade educacional, pois está mais voltada a avaliar a escola do que o processo de ensino, desconsiderando fatores intervenientes no ensino-aprendizagem, como condições socioeconômicas, estrutura familiar, localidade da escola, entre outros.

\footnotetext{
${ }^{1}$ Doutor em Ciências da Religião PUC - GO; Mestre em educação, PUC-GO; Pesquisador do tema "Cultura midiática, economia religiosa e juventude" - Universidade Estadual de Goiás - UEG/GO http://lattes.cnpq.br/3455052974561633 E-mail. pedrosahium@gmail.com

2 Licenciada em Pedagogia, na Faculdade do Noroeste de Minas - FINOM. E-mail: dlaudiapereira24vzt@gmail.com

3 Licenciada em Pedagogia, na Faculdade do Noroeste de Minas - FINOM. E-mail: iris_lgcelular@hotmail.com
} 
Palavras-chave: Avaliações Externas. Educação Básica. Apropriação dos Resultados. Prática Docente. Qualidade do Ensino.

ABSTRACT: The search for quality education in basic education in public schools is a challenge in the country. External evaluations have been a recurring tool in an attempt to solve problems with more assertive measures. The purpose of this study is to address how the results of external evaluations are appropriated by Basic Education teachers, based on the improvement of students' teaching-learning. The text was produced from an exploratory and qualitative bibliographic research. Addressing this theme is relevant because, in addition to being a current and necessary issue in the country, it is enriching in the academic context. The results point to external evaluations, however, with little efficacy in improving educational quality, as it is more focused on evaluating the school than the teaching process, disregarding factors involved in teaching-learning, such as socioeconomic conditions, family structure, school location, among others.

Keywords: External Assessments. Basic education. Appropriation of Results. Teaching Practice. Teaching Quality.

\section{Introdução}

A falta de qualidade da educação básica é um problema que está muito presente nas escolas públicas brasileiras, com resultados bem preocupantes, como, por exemplo, alunos já na segunda etapa do Ensino Fundamental sem o domínio das habilidades de leitura e escrita (FREITAS, 2019).

A recorrência do problema tem causado preocupação aos que trabalham, orientam e coordenam a educação básica. Em vista disso, as avaliações externas, também conhecidas como avaliações em grande escala, têm sido uma ferramenta empregada na busca da melhoria da educação e dos sistemas educacionais, tanto à nível de estado quanto pela União, que, por sua vez, tendem a se estruturar com proximidade aos objetivos estratégicos das políticas 
educacionais, por viabilizarem uma forma de aferir a qualidade que se busca - e necessita - na educação brasileira (BORGES, 2019). Mas, contudo, as avaliações implantadas pelos governos para investigar a educação têm apresentado números desanimadores.

As avaliações externas são instrumentos usados pelos governos, através dos seus órgãos educacionais, para aferir o desempenho das escolas e redes de ensino com a mensuração estatística da qualidade, condicionando segurança e assertividade às intervenções necessárias à melhoria da educação. A princípio, atende à necessidade de monitorar as redes de ensino e permitir aos gestores, professores e demais envolvidos no processo educativo repensarem a prática escolar diante da melhoria do ensinoaprendizagem dos alunos. A disseminação das avaliações externas visam, em tese, obter resultados do que se trabalha nas escolas e o desempenho dos alunos, porém, na maioria das vezes, não se findam nesse propósito, ficando restrita mais ao trabalho realizado pelo professor, sem afetar precisamente o desenvolvimento do ensino e as almejadas melhorias na educação levada para a sala de aula (BORGES, 2019).

Atualmente, há ainda uma necessidade eminente de as avaliações externas, em todos os níveis da educação, conquistarem uma legitimidade política e pedagógica frente à comunidade dos profissionais da educação, comunidade esta que menos tem se apropriado das conquistas alcançadas nessa modalidade de avaliação. Assim sendo, requer-se um novo olhar sobre essas avaliações, de forma que não seja instrumentalizada apenas para desenhar um perfil da educação brasileira, mas para se firmar e redirecionar a educação no país, tendo em vistas a situação precária das escolas públicas, tanto na sua estrutura física e capacitação quanto nos resultados apresentados às comunidades onde atuam.

Considerando esse contexto, este estudo é relevante porque vem trazer a discussão de uma temática atual, ou seja, a melhoria da qualidade da educação pública, que aflige todos os atores envolvidos no processo de ensino-aprendizagem das escolas. Contudo, trata-se de um aporte teórico que permite ao professor a apropriação devida 
dos resultados das avalições externas e o aproveitamento deles em favor de uma prática docente que melhore a qualidade do ensino.

Diante do exposto, o presente estudo aborda a apropriação dos resultados das avaliações externas pelos professores da Educação Básica, com base na melhoria do ensino-aprendizagem dos alunos. Especificamente, apresenta o Sistema de Avaliação da Educação Básica e suas avaliações padronizadas, os aspectos positivos e negativos do sistemas para o alcance dos seus propósitos, bem como ajudar a prática docente, no cotidiano da escola e, consequentemente, trazer melhoria à qualidade do ensino e aprendizagem dos alunos. Para tanto, é apresentada uma pesquisa bibliográfica, de abordagem exploratória qualitativa, buscando uma sustentação teórica à temática proposta, a partir de estudos e pesquisas divulgados em sites, revistas e material impressos já apresentados por diversos autores.

\section{O Sistema de Avaliação da Educação Básica e a prática escolar: aspectos gerais}

De início, antes da definição de avalições externas e os mecanismos que a estruturam no âmbito da educação brasileira, é preciso compreender o papel da avaliação, de modo geral. Sucintamente, a avaliação é um instrumento com propósito de apresentar resultados que possam determinar ações, as quais se findam no planejamento de novas ações. $\mathrm{Na}$ definição de Oliveira (2008, p. 9), a avaliação é uma ferramenta que busca "refletir sobre uma determinada realidade, visto que os dados e informações gerados pela avaliação possibilitam um julgamento que conduz a uma tomada de decisão" pelo professor na sua prática.

No entendimento de Mateus (2014), a avaliação é uma ferramenta utilizada pelo professor, que possa aferir o aprendizado alcançado pelos alunos e permita-lhe adotar novas práticas para conseguir a qualidade necessária para o ensino-aprendizagem na sala de aula. Nesse sentido, pode-se explicitar:

A avaliação é uma apreciação qualitativa sobre dados relevantes do processo de ensino-aprendizagem que auxilia o professor a tomar decisões sobre o seu

Educação In Loco, v.01, n. 01, jan.-jun. 2020 
trabalho. Os resultados dessa prática devem ser encarados como manifestações das situações didáticas, nas quais o professor e os alunos estão empenhados em atingir os objetivos de ensino. A análise da qualidade desses dados, feita por meio de provas, exercícios, tarefas, respostas dos alunos, etc., permite uma tomada de decisão para o que deve ser feito em seguida (LUCKESI, 2005 apud MATEUS, 2014, p. 143-144).

A finalidade da avaliação é aferir o aprendizado dos alunos diante dos conteúdos trabalhados na sala de aula, adotando critérios e instrumentos que se pautam no plano de trabalho e em documentos orientadores da educação nacional. Contudo, esse tipo de avaliação é direcionada, mais precisamente, à análise do professor sobre sua prática, o método de ensino e o que foi aprendido pelo aluno diante dos conteúdos programados.

Ao contrário da avaliação interna que está mais centrada na atuação do professor e o que está sendo ensinado na sala de aula, as avaliações externas ultrapassam o espaço escolar, com resultados sobre as condições das redes de ensino, modelo de gestão escolar, níveis de desempenho e aprendizado dos alunos, monitoramento dos programas educacionais, metas das políticas públicas educacionais, características socioeconômicas das escolas e alunos, entre outros aspectos. Sobre as avaliações externas, Machado (2012, p. 71), as definem como "processo avaliativo do desempenho das escolas desencadeado e operacionalizado por sujeitos alheios ao cotidiano escolar".

No Brasil, as avaliações em larga escala tiveram início na década de 1990, com a criação do Sistema Nacional de Avaliação da Educação Básica (SAEB). De âmbito nacional, essas avaliações se propunham a diagnosticar a situação da aprendizagem dos alunos e as redes de ensino, sendo que, de início, avaliavam-se $1^{\circ}, 3^{\circ}, 5^{\circ}$ e $7^{\circ}$ anos do Ensino Fundamental das escolas públicas, e, a partir daí, obtinham dados estatísticos retratando a realidade educacional dos estados e regiões do país (BORGES, 2019). 
O SAEB constituía-se de três formas de provas avaliando a educação pública em todas as esferas governamentais e os resultados passaram, a partir de 2007, a ser utilizados para calcular o Índice de Desenvolvimento da Educação Básica (IDEB), que é um indicador com dois conceitos igualmente importantes à qualidade do ensino oferecido nas escolas: o fluxo escolar e as médias de desempenho nas avaliações (FRANÇA, 2019).

A partir da criação do SAEB, as avaliações externas gradativamente passaram por mudanças, em conformidade com as necessidades advindas da situação da educação em todo país. Com isso, passaram a ser avaliadas as etapas finais dos ciclos educacionais, ou seja, o $5^{\circ}$ e o $9^{\circ}$ anos, do Ensino Fundamental, e o $3^{\circ}$ ano do Ensino Médio. Nesse mesmo período, cada estado brasileiro passou a implementar também as próprias avaliações, como aconteceu em Minas Gerais, na adoção do Sistema Mineiro de Avaliação e Equidade da Educação Pública (SIMAVE).

Para Castro (2009, p. 5, apud BORGES, 2019), o Sistema era visto como meio de sustentação de um "processo de formulação e monitoramento de políticas públicas responsáveis e transparentes", com a finalidade de "nortear o aprimoramento de ações de melhoria da aprendizagem" nas escolas públicas mineiras.

Naquela época, os sistemas de avaliação em larga escala objetivavam apresentar, de forma consolidada, dados obtidos do ensino no país, favorecendo, em tese, o acompanhamento do processo de ensino e aprendizagem nas escolas públicas, permitindo apesentar uma visão minuciosa das especificidades de cada escola e de seus alunos, como a questão de turnos, anos/séries, distribuição de turmas, questões socioeconômicas, entre outras.

Geralmente, essas avaliações traziam o propósito de aferir o desempenho dos alunos e avaliar escolas e redes de ensino, com a possibilidades de fornecer dados importantes para intervenções e distribuição de benefícios às próprias escolas avaliadas (BAUER; GATTI; TAVARES, 2013).

Na concepção de Bauer, Gatti e Tavares (2013), as avaliações de larga escala apontavam dados que permitiam aos governos reformas educacionais, bem como possibilitavam a efetivação de 
mudanças nas práticas escolares com a participação dos profissionais envolvidos no processo de ensino e aprendizagem, porém, contrapondo interesses de mecanismos internacionais impostos à educação brasileira, como subsidiar novas práticas apoiadas na dominação político-ideológica. Para essas autoras, entre tantas mudanças necessárias à qualidade da educação pública no país, havia a necessidade de pensar inicialmente no afastamento dos interesses internacionais impostos às políticas educacionais brasileira.

Porém, sabemos que as avaliações externas assumem grande importância na educação do país, fazendo-se necessário, além de governos e órgãos realmente preocupados com a falta da qualidade educacional, gestores escolares, professores e pais de alunos, que, por sua vez, estão mais próximos da realidade escolar, também se atentem às imperfeições apresentadas pelos sistemas de avaliações. Numa análise mais profunda, essas avaliações não apontam com razoabilidade aspectos que também afetam a escola, como as condições socioeconômicas dos alunos, fatores demográficos, a falta de capacitação dos professores diante dos problemas que circundam a escola e comunidade escolar, entre outros, que, por sua vez, são específicos a cada região e localidade e não elencados nos boletins levantados a partir dos resultados das avaliações (BORGES, 2019).

É claro que avaliar alunos e redes de ensino é importante, mas não o suficiente para identificar os problemas afetos à educação brasileira, que são mais abrangentes e complexos, cuja articulação englobam outros aspectos relevantes à qualidade esperada. Como exemplo, pode-se apontar as avaliações externas, em Minas Gerais, a partir dos anos 90, influenciadas pela política neoliberal impostas às escolas pelo Programa de Avaliação da Rede Pública da Educação Básica (PROEB), que objetivava claramente o controle do ensino, trazendo, no seu bojo, a responsabilidade de alcançar melhor produtividade e, consequentemente, melhor eficiência, e, assim, o status de educação com transparência da ação pública e eficácia dos resultados. Pautada em pressupostos educacionais, via-se nessa política de avaliações um regulador da prática docente, não um instrumento de melhoria da educação (SANTOS, 2010). 
Em relação ao PROEB, pode-se observar que não só determinava o conteúdo a ser promovido nas escolas, com o rol das habilidades e competências para os alunos, e envolvia também aspectos sobre atuação do professor diante das suas atividades. Além do mais, as habilidades e competências eram vistas de forma fragmentada, incompleta e limitada sobre os conhecimentos que os alunos deviam dominar na formação escolar.

Assim, mesmo compreendendo a avaliação externa como instrumento voltado à melhoria na qualidade da educação, o modelo de avaliação do PROEB não levava em consideração as diversas complexidades envolventes do processo educativo, focando no resultado sem perspectiva de orientação para que se buscasse, de fato, uma educação de qualidade. Nesse sentido, o PROEB "não oferece critérios legítimos para avaliar a qualidade da educação ofertada, compreendendo por educação de qualidade aquela que oferece uma formação histórico-cultural que atenda às necessidades e expectativas dos alunos e da comunidade escolar" (SANTOS, 2010, p. 9).

Vale dizer ainda acerca do PROEB que, além de alvejar a produtividade e a eficiência da educação na escola pública, o programa concebia a "premiação" das escolas com resultados satisfatórios nas avaliações externas, ou seja, o direito ao recebimento de bonificações, que mais serviam de ferramenta para "culpar" as escolas com baixo desempenho nos resultados, independente dos elementos externos influenciadores do trabalho diário, como as particularidades de cada escola, situação econômica da comunidade escolar, etc. (SANTOS, 2010).

Embora o discurso das avaliações em grande escala assumissem, com base nos seus propósitos, a busca da melhoria da qualidade do ensino, a partir dos seus resultados, Santos (2010) entende que, na prática, os resultados iam numa outra linha de pensamento, isto é, as medidas tomadas com os resultados obtidos não eram empregados em prol dos interesses e reais necessidades de cada escola, mas com foco nos interesses neoliberais atendiam exigências e as demandas do capital. 
Há diversos estudos que apontam as avaliações externas como importantes para a educação pública, não podendo ser ignoradas no ensino-aprendizagem. Para o Instituto Unibanco (2016, p.2), os resultados dessas avaliações possibilitam "uma ferramenta para subsidiar tomadas de decisões no âmbito dos sistemas educacionais ou em cada escola, sendo uma prática que estudos demonstram estar associada a redes e escolas com melhores resultados de aprendizagem".

Quando bem interpretados e apropriados levando em conta limites e possibilidades, os resultados podem fortalecer a ação gestora da escola, a atuação docente e o ensino com qualidade. Contudo, é preciso que tanto gestores quanto professores conheçam as especificidades da política das avaliações, observando-as de forma crítica e aberta, para que possam extrair delas dados em prol da qualidade do ensino público e do mapeamento dos diversos desafios interventores na qualificação educacional.

Um aspecto importante ressaltado nas avaliações externas é a implantação da Plataforma Devolutivas Pedagógicas ${ }^{4}$, pelo Instituto Nacional de Estudos e Pesquisas Educacionais Anísio Teixeira (INEP), a partir de 2015, com o propósito de ajudar a equipe pedagógica das escolas com disponibilização de dados sobre distribuição dos estudantes por níveis de proficiência.

Essa plataforma apresenta diagnósticos da educação, que viabilizam identificar as desigualdades nas escolas e reorientar o trabalho docente, por meio de comentários pedagógicos e de estatísticas frente às respostas dos estudantes na Prova Brasil/SAEB. Trazem uma aproximação das avaliações externas ao contexto escolar, ajudando a equipe pedagógica no planejamento de ações com vistas à melhoria da aprendizagem dos alunos (INSTITUTO UNIBANCO, 2016).

De modo geral, os sistemas de avaliações vêm se desenvolvendo, ao longo dos anos, implementando políticas cada vez mais consistentes e eficazes ao aprimoramento e melhoria da atuação

\footnotetext{
${ }^{4}$ A Plataforma Devolutivas Pedagógicas aproxima as avaliações externas de larga escala e o contexto escolar, tornando os dados coletados mais relevantes para o aprendizado dos alunos. A partir da disponibilização dos itens utilizados na Prova Brasil, descritos e comentados por especialistas, a Plataforma traz diversas funcionalidades que poderão ajudar professores e gestores a planejar ações $\mathrm{e}$ aprimorar $\mathrm{o}$ aprendizado dos estudantes. http://portal.inep.gov.br/devolutivas
}

Educação In Loco, v.01, n. 01, jan.-jun. 2020 
dos governos na qualidade do ensino. O SAEB, como foi apresentado, assume um papel fundamental no debate dos sistemas de avaliação em larga escala. Trouxe um suporte para se conhecer o ensino e determinar, com mais profundidade, o debate sobre melhorias a serem implementadas, bem como instituir outros diversos sistemas de avaliação pelos estados e municípios brasileiros. No todo, trouxe contribuições para um amplo debate sobre o trabalho didático-pedagógico nas escolas, visto que, a partir da estruturação de desempenho, habilidades e competências, a escola e redes de ensino passaram a ser diagnosticadas, bem como levantados seus percalços e possibilidades de melhorias educacionais (PONTES, 2012).

Os sistemas de avaliações padronizados apontam dados sobre a realidade das escolas a partir do questionário contextual aos alunos, professores e gestores, possibilitando conhecer a realidade de cada escola e local onde está inserida. Desse modo, tornam-se uma ferramenta para se prestar contas à sociedade e ao debate público frente aos desafios educacionais no país. Mas, segundo Pontes (2012), as metas educacionais não podem ser firmadas com base apenas nos resultados das avaliações, uma vez que, mesmo diante de tantas avaliações já realizadas e estudos apresentados, os alunos ainda continuam com deficiência em leitura, escrita e resolução de problemas.

Até aqui, observa-se que os resultados das avaliações externas, de modo geral, findam-se em direcionar um posicionamento didático-pedagógico orientador da prática docente $\mathrm{e}$ do aprendizado do aluno, não considerando outros problemas que afetam a escola. Noutras palavras, Resende (2014 apud BORGES, 2019) observa as avalições apenas como diagnóstico para se adotar estratégias de ensino, mas que podem ser ponto de partida para se planejar o trabalho pedagógico. A proposta do SAEB, numa visão mais ampla, foi o acompanhamento da qualidade da Educação Básica, permitindo que fossem diagnosticados os problemas do ensino nas escolas públicas e a definição de ações voltadas à solução deles, bem como orientar a formulação e implementação de políticas educacionais mais eficazes. 
As primeiras avaliações do SAEB foram aplicadas para as $1^{\text {as }}$, $3^{\text {as }}, 5^{\text {as }}$ e $7^{\text {as }}$ séries e depois passaram a avaliar o $6^{\text {os }}$ e $8^{\text {os }}$ anos do Ensino Fundamental das escolas públicas urbanas nas disciplinas de Língua Portuguesa, Matemática, Ciências e Redação. Em 1995, visando o aprimoramento na análise dos dados coletados, melhorias frente à metodologia empregadas nas avaliações e uma comparabilidade dos resultados, foram feitas mudanças importantes, entre elas, o uso da Teoria de Resposta ao Item (TRI) na construção e análise dos resultados dos testes, processando-se também a verificação de dados contextuais, através de questionários, que permitiam a comparação com os resultados dos anos anteriores (BORGES, 2019).

A TRI foi empregada para mensurar a proficiência do aluno e, por meio dela, identificar sua compreensão acerca de um determinado conteúdo estudado, identificando o que foi aprendido e o que precisaria ainda ser ensinado pela escola. Em suma, a interpretação da escala de proficiência (TRI) se dá a partir dos resultados da medida da habilidade do aluno no seu desenvolvimento cognitivo e educacional, permitindo categorizá-lo num determinado padrão de desempenho (SIMAVE, 2016). Assim, a escala de proficiência pode ser explicada:

Essa metodologia nos permite colocar, em uma mesma escala (régua), os itens e as habilidades dos estudantes. A partir de pré-testes, definimos a proficiência dos itens e a dos estudantes também, o que nos possibilita alocá-los, conforme a sua proficiência, em um ponto da régua, em geral, numerada de 0 a 500 (Proeb) ou de 0 a 1000 (Proalfa). [...] Nessa régua (escala) os valores obtidos nos testes são ordenados e categorizados em intervalos ou faixas que indicam o grau de desenvolvimento das habilidades para os estudantes que alcançaram determinado nível de desempenho (SIMAVE, 2016).

Nesse entendimento, observa-se que, ao se dispor itens e alunos numa mesma escala, são obtidas informações importantes sobre o desenvolvimento das habilidades avaliadas. Em relação ao 
aspecto pedagógico da escala de proficiência, é visto que cada nível corresponde a diferentes características de aprendizagem, sendo que, quanto maior o nível na escala, maior probabilidade de desenvolvimento e consolidação da aprendizagem. Contudo, a escola passa a ter medidas em diagnósticos qualitativos do desempenho escolar. Nesse aspecto, a Escala de Proficiência possibilita a identificação das habilidades não desenvolvidas pelo aluno dentro das disciplinas avaliadas, o que a torna uma importante ferramenta à prática docente, pois possibilita ao professor o planejamento e a execução de ações que atendem mais precisamente a necessidade de cada aluno (SIMAVE, 2016). Aplicada adequadamente, a avaliação externa permite a compreensão do que está sendo aprendido pelo aluno.

Em 1997, houve mudanças nos anos para as avaliações do SAEB, cujo propósito foi dar maior precisão técnica à construção dos itens e análise dos resultados. As avaliações passaram a ser feitas nos anos das etapas finais dos ciclos de escolarização, nas $4^{\mathrm{a}}$ e $8^{\mathrm{a}}$ séries, que são atualmente o $5^{\circ}$ e $9^{\circ}$ anos do Ensino Fundamental, e no $3^{\circ}$ ano do Ensino Médio. Também passaram avaliar a rede particular de ensino e o desenvolveram as matrizes de referência, favorecendo pontos importante da avaliação para compreender quais habilidades e competências devem ser mensuradas para determinada série. Nesse ano, avaliou-se também as disciplinas de Física, Química e Biologia, no Ensino Médio. E dois anos depois, foram incluídas as disciplinas de Geografia e História. Esse formato perdurou até 2001, com o Plano Nacional de Educação (PNE), que passou a priorizar apenas as disciplinas de Língua Portuguesa e Matemática (BORGES, 2019).

Com o PNE, estabelecido pela Lei Federal no 10.172/2001, o SAEB foi consolidado como sistema de avaliação da educação pública, havendo, portanto, a garantia do acompanhamento permanente da situação escolar no país (BRASIL, 2001). Assim, o PNE determinava claramente:

A consolidação e o aperfeiçoamento do censo escolar, assim como do Sistema Nacional de Avaliação da Educação Básica (SAEB), e a criação de sistemas complementares nos Estados e Municípios permitirão 
um permanente acompanhamento da situação escolar

do País, podendo dimensionar as necessidades e perspectivas do ensino médio e superior (BRASIL, 2001, p. 19).

Novamente, em 2005, com base na Portaria do Ministério da Educação e Cultura (MEC) no 931, o sistema de avaliação se reestruturou com dois processos de avaliação: a Avaliação Nacional da Educação Básica (ANEB) e a Avaliação Nacional do Rendimento Escolar (ANRESC). Nessa reestruturação, a ANEB/ANRESC manteve os procedimentos da avaliação amostral adotados pelo SAEB, enquanto a ANRESC/Prova Brasil passou a ser uma avaliação censitária para as instituições com minimamente 20 alunos, no final dos anos iniciais ( $5^{\circ}$ ano) ou do $9^{\circ}$ ano do Ensino Fundamental das escolas públicas, viabilizando, portanto, resultados específicos por escola (BORGES, 2019).

Em 2013, a Portaria do MEC no 482 reestruturou novamente o SAEB com a avaliação das séries iniciais do Ensino Fundamental, através da Avaliação Nacional da Alfabetização (ANA), advinda do Pacto Nacional pela Alfabetização na Idade Certa (PNAIC). Além disso, incluiu-se a avaliação da disciplina de Ciências, sob caráter experimental, para o $9^{\circ}$ ano do Ensino Fundamental, e para o $3^{\circ}$ ano do Ensino Médio. Nessa reestruturação, o SAEB se estabeleceu no atendimento a todas as etapas com a Avaliação Nacional da Educação Básica (ANEB), isto é, a ANRESC/Prova Brasil avaliando nacionalmente o rendimento escolar e a ANA, avaliando o nível da alfabetização. Com isso, o governo detinha o diagnóstico preciso de toda a situação da educação básica no país (INEP, 2017).

No ano de 2019, a proposta do Instituto Nacional de Estudos e Pesquisas Educacionais Anísio Teixeira (INEP) foi avaliar a Educação Infantil (creche e pré-escola), que era prevista desde 2010, pelas Diretrizes Curriculares Nacionais para a Educação Infantil, bem como no PNE. Não haveria provas, como nas demais avaliações do SAEB, mas a aplicação de questionários a professores, gestores e equipes das escolas infantis, bem como aos pais e responsáveis pelas crianças, avaliando aspectos referentes à infraestrutura, formação docente e oferta de brinquedos, entre outros, os quais são necessários 
para proporcionar o desenvolvimento ideal para as crianças. Isso porque o país possui atualmente $32 \%$ das crianças com até 3 anos de idade nas creches e $91,5 \%$ das crianças com 4 e 5 anos de idade na pré-escola, demonstrando a extrema necessidade de observar os fatores da qualidade educacional nessa etapa de ensino (FORMENTI; PALHARES, 2019).

Outra mudança apresentada, em 2019, foi a reformulação do SAEB pelo MEC, que suprimiu os nomes da Prova Brasil, ANA e outras determinando-as como etapas do Sistema de Avaliação da Educação Básica. A proposta é que as avaliações do SAEB aconteçam em seis etapas, sendo avaliadas a creche, a pré-escola, o $2^{\circ}$ ano do Ensino Fundamental, $5^{\circ}$ ano do Ensino Fundamental, $9^{\circ}$ ano do Ensino Fundamental e, por fim, o $3^{\circ}$ ano do Ensino Médio, com acontecimento de dois em dois anos, nos anos ímpares, e a divulgação feitas nos anos pares (TOKARNIA, 2019).

Em 2019, não houve a Avaliação Nacional da Alfabetização, que está prevista para 2020, e não será mais aplicada no $3^{\circ}$ ano do Ensino Fundamental e acontecerá, como visto anteriormente, no $2^{\circ}$ ano, com crianças de 7 anos de idade. Essa mudança fará a adequação da avaliação do SAEB à Base Nacional Comum Curricular (BNCC), cuja homologação aconteceu em 2018, estabelecendo os conteúdos mínimos a serem ensinados nas escolas de todo o país. Isso porque, segundo a $\mathrm{BNCC}$, os alunos deverão aprender a leitura e escrita até o $2^{\circ}$ ano do Ensino Fundamental, além de conteúdos de estatísticas e probabilidade (TOKARNIA, 2019).

Com relação as avaliações da Prova Brasil, que geralmente aconteciam no $5^{\circ}$ e $9^{\circ}$ ano do Ensino Fundamental, continuarão a existir, porém com a respectiva denominação de $4^{\mathrm{a}}$ e $5^{\mathrm{a}}$ etapas do $\mathrm{SAEB}$, avaliando as habilidades dos alunos na Língua Portuguesa e Matemática, mas, para o $9^{\circ}$ ano do Ensino Fundamental, serão avaliados conteúdos de Ciências da Natureza e Ciências Humanas. O fato dessa mudança é a busca da educação brasileira à compatibilidade com avaliações internacionais, como o Programa Internacional de Avaliação de Estudantes (PISA), aplicado pela Organização para Cooperação e Desenvolvimento Econômico (OCDE) aos alunos com 15 anos de idade em vários países do 
mundo, incluindo o Brasil, que, em 2015, posicionou-se no $63^{\circ}$ lugar na disciplina de Ciências, num total de 70 países. A competência do aluno avaliado em Ciências não será empregada no cálculo do IDEB, um indicador de qualidade da educação no país, mas é esperado que a disciplina de Ciências seja incluída no IDEB, a partir de 2023 (FORMENTI; PALHARES, 2019).

\section{O SAEB na prática docente e na qualidade do ensino e aprendizagem}

A Prova Brasil, ANA, IDEB, entre outras avaliações que buscam aferir a qualidade da educação no país, por si só, não são efetivas quanto à melhoria esperada na qualidade da educação, o que se avista é a necessidade de uma análise bem profunda dos resultados de todas as avalições externas, sobretudo, na Plataforma Devolutivas Pedagógicas, a qual dispõe de dados da distribuição dos alunos por níveis de proficiência e comentários pedagógicos e de estatísticas relacionados aos resultados das avaliações. Saber analisar os resultados das avaliações externas para que se possa aprimorar a prática docente e o ensino-aprendizagem é desafiante a gestores, professores, coordenadores pedagógicos e técnicos.

Para tanto, faz-se necessário uma boa leitura e a análise aprofundada dos boletins contendo esses resultados e, a partir deles, abrir debates entre os envolvidos no processo educativo, de modo a viabilizar a preparação de um plano para transformá-los numa prática escolar mais efetiva e voltada às reais necessidades para a qualidade do ensino (NOVA ESCOLA, 2019).

Vale observar que a apropriação de resultados das avaliações externas não significa apenas levar ao conhecimento das escolas a divulgação dos resultados, mas deve proporcionar o debate entre os envolvidos no processo educativo escolar, de maneira que juntos possam avistar as diversas possibilidades de intervenções pedagógicas. Segundo Marques (2017), o gestor escolar, juntamente ao coordenador pedagógico, tem papel importante na disseminação das informações obtidas nos resultados das avaliações, verificando como estão sendo apropriadas pelos professores e, a partir daí, ajudá- 
los a reorientar suas práticas pedagógicas. A reflexão sobre esses resultados pode subsidiar ações colaborativas, com medidas interventivas no processo de ensino-aprendizagem em todas a áreas do conhecimento, mas, para isso, é necessário que as escolas não tenham esses resultados apenas sob fins classificatórios, como tem acontecido comumente.

Os resultados das avaliações externas divulgados nos boletins da Plataforma Devolutivas Pedagógicas devem ser analisados e acompanhados, segundo Borges (2019, p. 79), de um planejamento com ações que se iniciem com "o mapeamento das falhas, através de discussões colaborativas voltadas aos resultados, priorizando o embate de ideias dos envolvidos na apropriação, para, na sequência, implementar ações de intervenção positiva frente aos pontos determinados prioritários".

Os resultados das avaliações só serão significativos no trabalho da escola, se as informações obtidas forem conhecidas, diagnosticadas e analisadas pela escola, oportunizando, desse modo, o aprimoramento e o redirecionamento da prática docente para alavancar ainda mais o aprendizado dos alunos frente as avaliações padronizadas e, até mesmo, nas avaliações internas. Para tanto, é necessário que o docente se aproprie dos resultados retratados nos boletins de forma reflexiva e compartilhada.

Ao abordar acerca da importância da apropriação dos resultados como subsídios às ações pedagógicas da escola e da prática docente, Machado (2012) observa que, para terem efeitos na prática, é preciso que sejam bem interpretados e utilizados na implementação de novas práticas e ações dentro da escolas, envolvendo todos os que participam do processo educativo, ou seja, gestores, professores, coordenadores pedagógicos e até a própria comunidade escolar, através do conselho de pais, e a participação de todos no Projeto Político Pedagógico. Noutra linha, essa autora deixa críticas, em alguns casos, em que os resultados podem aparecem como instrumento à competitividade entre as escolas, enfraquecendo a busca da qualidade que se espera na educação brasileira.

De acordo com Machado (2012), no que tange aos aspectos negativos da apropriação dos resultados, em muitos casos, existem 
escolas que, ao invés de implementar novas ações voltada à melhoria do ensino e aprendizagem, numa linha contrária à propostas das avaliações por parte do INEP, se direcionam na instrução, treinamento e disciplina dos alunos focando mais nos conteúdos cobrados nas avaliações, afastando-se dos propósitos de buscar na observação, reflexão, comunicação, motivação e experiência a melhoria da qualidade do ensino levado para a sala de aula.

Isso significa dizer a importância da escola focar no trabalho pedagógico direcionado ao desenvolvimento de habilidades e competências necessários aos alunos para que atuem como sujeitos históricos no meio onde estão inseridos, na sociedade repleta de problemas que requerem soluções, que talvez não sejam próprias somente da escola, mas que ela seja intermediadora de um conhecimento na busca de solucioná-los.

$\mathrm{O}$ gestor deve atentar-se à média de sua escola, visto que, ao identificar o desempenho da escola é aberta a possibilidade de compará-la a outras escolas e, com isso, possibilitará a troca de experiências de ações pedagógicas que possam alavancar a melhoria da escola onde atua. Além do mais, a leitura de dados, diagnósticos e plano de ações são medidas que possibilitam reais mudanças no ensino e aprendizagem.

Nesse aspecto, é importante citar a criação do Programa Avaliação e Aprendizagem de iniciativa da Fundação Itaú Social, sob a coordenação técnica da Comunidade Educativa (CEDAC), cujo propósito é contribuir à ampliação do uso pedagógico dos resultados das avalições externas com as secretarias municipais e estaduais de educação, através do desenvolvimento de ações voltadas à qualidade educacional (NOVA ESCOLA, 2019).

De acordo com Silva e Gimenes (2019), existem falhas em relação à produção de materiais didáticos, que buscam enfatizar mais a relação entre os conteúdos curriculares desenvolvidos na sala de aula com os resultados das avaliações externas. Enfatizar mais os conteúdos trabalhados nas aulas com vistas na matriz de referência das avaliações externas pode resultar no reducionismo do currículo escolar, o que, por sua vez, mostra-se uma reconfiguração do currículo, reduzindo-o à apenas nas competências e habilidades 
avaliadas, fragmentando o ensino e privando o aluno do acesso aos conhecimentos importantes no seu processo de formação escolar. Afastar-se da base curricular e manter-se a preocupação no preparo dos alunos para as avaliações externas faz o ensino perder sua essência, ou seja, a implementação de um ensino-aprendizagem centrado no pedagógico, no desenvolvimento do aluno para o crescimento como ser social.

Refletir sobre os resultados das avaliações externas é um procedimento importante ao corpo docente nas escolas, pois trazem o desempenho delas diante das políticas educacionais e sua efetivação na prática. Assim, os resultados assinalam informações e ações importantes que devem compor o trabalho pedagógico, fortalecendo principalmente o que está proposto nos Conteúdos Básicos Comuns e no Projeto Político Pedagógico, para que, a partir daí, estruturem ações a favor da melhoria do ensino e aprendizagem.

Ademais, os resultados das avaliações, por meio do debate dos boletins pedagógicos, possibilitam aos professores o acompanhamento do desempenho dos alunos e, consequentemente, intervir com medidas que alavanquem melhoria no rendimento escolar deles, como, por exemplo, a produção de material didático aliado ao currículo escolar e aos resultados das avaliações. Desse modo, os resultados das avaliações externas podem trazer o fortalecimento do aprendizado do aluno e da própria instituição (BORGES, 2019).

Um fator observado por Borges (2019) é que, ao realizem simulados no intuito de "treinar" os alunos para as avaliações externas, esses simulados podem ser um aspecto positivos como didática e prática de ensino. Nesse aspecto, esse autor destaca que esses simulados podem favorecer modificações nas formas das avaliações internas; aprimorar as matrizes de avaliação do planejamento dos professores; abrir debates a partir da análise e interpretação dos resultados das avaliações por todos os atores envolvidos no processo educativo; diversificar as atividades pedagógicas aplicadas nas escolas; proceder, de forma indireta, a auto avaliação da própria prática docente frente aos resultados; expor 
as condições da escola tanto aos alunos quanto aos pais ou responsáveis; entre outras.

De acordo com o Programa Educação para Todos (2019), de alguma forma os resultados das avaliações ajudam os professores a aprimorarem sua prática, embora recomendam cautela na sua adoção. Nesse caso, recomenda-se que o uso dos resultados das avaliações favoreça um plano de ação bem elaborado e colocado na prática com base no diagnóstico obtido dos resultados, assegurando, assim, a melhoria das condições de ensino e aprendizagem, não considerando apenas a melhoria da nota mediante essas avaliações.

O Programa aponta ainda ações e discussões pelos professores, a partir do portal Devolutivas Pedagógicas das Avaliações, observando criteriosamente as habilidades e competências que possivelmente precisam ser trabalhadas pela escola, além da comparação dos resultados entre as avaliações externas e as internas, levantando as demandas da escola e da prática na sala de aula, sobretudo, aquelas voltadas à melhoria das condições de ensino da Leitura e de Matemática.

\section{Metodologia}

Na busca de uma abordagem teórica que responda à questão da apropriação dos resultados das avaliações externas na prática docente na Educação Básica, o presente estudo é apresentado a partir de uma pesquisa bibliográfica, de cunho exploratório e qualitativo, sob a visão de diversos autores acerca dessa questão. Contudo, a metodologia compreendeu um levantamento de publicações na base de dados Google Acadêmico (https://scholar.google.com.br/), da ScientificElectronic Library Online - SciELO (http://scielo.br/) e Portal de Periódicos Capes (http://www.periodicos.capes.gov.br/), bem como em livros, revistas e outras publicações impressas, objetivando identificar trabalhos científicos, buscando atingir os objetivos propostos neste estudo.

A pesquisa bibliográfica, denominada também de revisão de literatura ou referencial teórico, trata-se de estudos, pesquisas, entre outros tipos de textos, com contribuições científicas de autores que 
dialogam entre si, e possibilitam a composição de um entendimento amplo e específico de determinado assunto. Assim, "é importante que na realização de uma Revisão Bibliográfica o acadêmico não construa apenas justaposições de trechos de autores, mas faça articulações entre as ideias dos mesmos, identificando suas posições teóricas semelhantes e divergentes". É fundamental essa articulação do assunto pesquisado para que se tenha, no todo, uma compreensão clara do assunto temático (SANTOS; CANDELORO, 2006, p.43).

Nesse caminho, ressalta-se que, para iniciar a pesquisa, foi realizado um levantamento de todas as publicações, sendo que, a partir da leitura dos resumos, arrolou-se aquelas que abordavam discussões importantes acerca do proposto na temática deste estudo. Feito isso, foram apontados vários textos que, após a realização da leitura de todos eles, procedeu-se à seleção e fichamentos das partes mais alusivas aos objetivos da pesquisa, de modo a estruturar, por fim, um texto que fosse de encontro à resposta para a questão levantada na parte introdutória destes artigo. Contudo, os autores estudados estão referenciados no final deste trabalho.

\section{Resultado e reflexões}

Acerca dos estudos abordados das avaliações externas e a apropriação dos resultados pelos professores para a melhoria da qualidade da educação básica, pode-se perceber, incialmente, que as avaliações de modo geral não são capazes de retratar com inteireza as verdadeiras demandas existentes nas escolas, que, por sua vez, afetam a prática docente e o ensino-aprendizagem, deixando de promoverem qualidade esperada. Apesar de trazer dados estatísticos e informações que podem auxiliar no enfrentamento dessas demandas, como melhorar o aprendizado dos alunos, os problemas socioeconômicos onde vivem, entro outros, ainda estão distantes do que se espera da educação e da prática docente, apesar de várias inovações já apresentadas.

Entretanto, não se pode negar que as avaliações externas detêm aspectos importantes à prática docente, desde a criação em 1990, quando o foco se dava mais em diagnosticar o desempenho dos 
alunos e das redes de ensino. A falta do debate entre os envolvidos no processo educativo da escola tem sido um dos entraves para que as avaliações possam, de fato, gerir resultados sirvam de caminhos para que se planeje aulas mais ricas e conteúdos interessantes e proveitosos aos alunos sob o aspecto do seu preparo para vivenciar e superar os diversos problemas presentes no meio onde se encontram.

Ademais, não há a discussão desses resultados visando a melhoria da educação, como o uso de um bom material didático, conteúdos curriculares baseados nas especificidades de cada escola e a capacitação dos professores, sobretudo, para que saibam interpretar os resultados e, a partir disso, aprimorar sua prática pedagógica.

É fato que, depois das primeiras avaliações do SAEB, gradativamente vieram mudanças, principalmente, com os estados implementando suas próprias avaliações, a exemplo, o SIMAVE, em Minas Gerais. Essas mudanças trouxeram novos processo de formulação e monitoramento de políticas educacionais no país, apresentando mais responsabilidade e transparência nos resultados e ações de melhoria do ensino-aprendizagem nas escolas, que, em tese, passaram a retratar mas detalhadamente o desempenho dos alunos e o trabalho das escola, sobretudo, com uso das Plataforma Devolutivas Pedagógicas e boletins. Com isso, vieram questionamentos importantes sobre turnos, anos/séries, formação de turmas, fatores socioeconômicos etc., os quais puderam ser avaliados e checados diante do trabalho diário das escolas e do que precisaria ser destacado e aprimorado na prática pedagógica. Além do mais, tudo isso possibilitou o desenho das escolas de modo a repensar as intervenções e distribuição benefícios a elas. Mas, contudo, o debate desses resultados não constava na agendo dos professores.

Sabemos que, numa visão mais específica, as avaliações externas subsidiavam dados aos governos para a adoção de políticas e reformas educacionais e, assim, ir ao encontro de um propósito maior: mudanças nas práticas escolares envolvendo os profissionais de educação nos resultados e, a partir delas, a melhoria da qualidade do ensino.

Porém, o fato de tudo isso não acontecer na prática era em razão de acordos firmados pelo país com mecanismos internacionais, 
sobretudos, com instituições financeiras que injetavam capital no país e, simultaneamente, impunham práticas alicerçadas em ideais político-ideológico de dominação. Nesse contexto, as questões da educação têm-se caracterizadas pela lógica dos interesses internacionais que a direciona mais para um produto, um modelo educacional ajustado aos interesses e exigências da economia neoliberal global, do que um ensino voltado à realidade vivenciada pelas escolas brasileiras e os ideais pedagógicos que atendam à formação humana.

Convém destacar que o país apresenta, de forma agravada, problemas característicos de países em desenvolvimento, como enorme desigualdade na distribuição da renda e imensa deficiências no sistema educacional, precisando, portanto, afastar as políticas educacionais da ideia simplista de que o problema da educação se resolve apenas oferecendo escolas, desconsiderando os aspectos da pobreza e da falta de qualidade educacional.

$\mathrm{O}$ fracasso das políticas educacionais, mesmo quando fundadas nos resultados das avalições em grande escala, está associado, na maioria das vezes, ao fato de não se propor uma política social abrangente e baseada na consciência dos impasses econômicos, políticos e culturais que permeiam nossa educação e precisam ser claramente enfrentados, para que se construa um sistema educacional efetivo, abrangente e realmente de qualidade, que se finda na transformação do ser humano.

Retomando as avaliações externas como importantes ferramentas ao trabalho do professor, é válido dizer que governos e órgãos competentes, gestores escolares, professores e pais de alunos, que, por sua vez, estão mais próximos à realidade escolar, precisam atentar-se às imperfeições apresentadas pelos sistemas de avaliações e possam extrair delas aspectos que permitem o mapeamento dos problemas enfrentados pela própria escola e os atores do processo educativo, buscando inovarem prática que alavanquem melhorias na qualidade do ensino-aprendizagem.

A Prova Brasil, ANA, IDEB e outros indicadores não são comprovadamente suficientes para melhorarem a qualidade da educação brasileira, sem que os professores (as) repensem suas 
práticas. É preciso que seus resultados dialoguem com os projetos e práticas docentes desenvolvidos pelas escolas, de forma que possam fazer as mudanças necessárias no contexto onde estão inseridas, sobretudo, trazendo mudanças no meio social onde se encontram os alunos.

Não se pode deixar de frisar que a Educação Básica vem passando por uma série de mudanças em razão das avaliações, que, por certo, vem interferir no trabalho docente. Mesmo com as avaliações externas que são propostas às escolas empregando o rendimento dos discentes para compor o IDEB, as avaliações internas assumem grande importância, no decorrer do curso, objetivando o acompanhamento da aprendizagem deles. As avaliações internas muitas vezes são desconsideradas e avaliações externas assumem o protagonismo dentro da escola, visto que são empregadas na avaliação do IDEB. Nesse entendimento, as avaliações externas, como a Prova Brasil e o SAEB, por exemplo, que tem finalidade de avaliar a qualidade educacional, finalizam na contradição ao quantificar o desempenho cognitivo do aluno, através de um índice de aprovação, ou seja, o IDEB. Se as avaliações tem fins diagnósticos do que está sendo ensinado, por que se valoriza apenas as notas finais para compor o IDEB? A maioria dos estudos realizados têm mostrado que os diagnósticos pouco têm sido considerados para fins de mudanças nas práticas docentes, na melhoria da qualidade do ensino.

Apesar das escolas com o IDEB maior receberem maior investimento à melhoria do ensino, há a problemática de as escolas que estão inseridas em contextos sociais e alunados diferentes, com realidades bem distintas umas das outras, no país, a exemplo, níveis socioeconômicos divergentes entre elas, acabam por serem avaliadas igualmente por essas provas de grande escala, o que, ao ver dos estudiosos, é um grande equívoco. Essa diferença deve ser vista quando realizada as avaliações de cada escolas pelos estados e governo federal. E indo mais além, cada escola precisa de investimentos diferentes, respeitando sempre suas especificidades.

Por fim, ressalta-se o posicionamento dos docentes diante as avaliações externas, o que já vem acontecendo em algumas escolas 
do país, de ressignificação do uso dos resultados obtidos, considerando-os para a capacitação docente, a compreensão mais ampla entre a matriz de referência e a curricular, sem que uma sobreponha a outra, e de modo que os docentes se apropriem desses resultados, transformando-os em melhoria de sua prática, com projetos interdisciplinares e novas estratégias de ensino, que busquem não apenas melhores índices (IDEB), mas o enriquecimento das aulas, melhor material didático, entre outros, $\mathrm{e}$, consequentemente, a melhoria do ensino. As avaliações externas devem se findar em ações pedagógicas que possam ir além das dificuldades cognitivas dos alunos, sendo, portanto, um processo reorientador da prática docente e, assim, podendo contribuir satisfatoriamente na melhoria da qualidade do processo ensinoaprendizagem.

\section{Considerações finais}

Diante dos objetivos propostos, o estudo permitiu observar que as avaliações externas buscam mais a quantificação do ensino, ao invés da qualificação das práticas escolares.

Destarte as escolas encontram dificuldades em rever sua atuação, não apenas diante dessas avaliações, mas, no cotidiano escolar, com considerações importantes sobre a formação e a capacitação dos docentes, a situação socioeconômicas dos alunos, que vão desde a estrutura familiar até a localidade onde está inserida a escola, e a qualidade das aulas que estão sendo ministradas em cada escola. Assim, pode-se dizer que estudo apontou para o fato de que as avaliações, apesar de importantes, ainda não são suficientes para melhorar a qualidade da educação brasileira, apresentando problemas na apropriação dos dados gerados e sua aplicação por parte dos docentes e da escola.

No âmbito dos resultados das avaliações externas, os diagnósticos produzidos pelos órgãos responsáveis, dão a impressão de que o todos os problemas enfrentados são dos professores e das escolas, que não preparam adequadamente os alunos (as) para que 
sejam uns sujeitos ativos e construtores de mudanças na sua própria história.

Os estudos abordados também deixam em evidência as muitas falhas dessas avaliações que precisam ser revistas, para que de fato para não apenas levantem índices avaliativos, mas apontem caminhos para que os professores possam repensar o seu trabalho e, com isso, refazerem suas práticas com vistas à melhoria da tão necessitada qualidade, ainda ausente na educação brasileira. Que as avaliações externas não sejam o fim de um caminho, apontando diagnósticos e índices, mas ferramentas para direcionar uma prática docente de qualidade, considerando todos os fatores que podem interferir no processo da aprendizagem dos alunos, sobretudo, aqueles que vêm de meios sociais precários e de famílias desestruturadas.

\section{Referências bibliográficas}

BAUER, Adriana; GATTI, Bernadete A.; TAVARES, Marialva (Org.). Vinte e cinco anos de avaliação de sistemas educacionais no Brasil. 1. ed. Florianópolis: Insular, 2013. p. 27-41.

BORGES, Ronaldo Martins. A apropriação de resultados do Sistema Mineiro de Avaliação (SIMAVE) no Ensino Médio: desafios e possibilidades para uma gestão colaborativa. 2019. $157 \mathrm{f}$. Dissertação. (Mestrado Profissional em Gestão e Avaliação da Educação Pública). Universidade Federal de Juiz de Fora.

BRASIL. Lei no. 10.172, de 9/1/2001. Estabelece o Plano Nacional de Educação. Diário Oficial da União, Brasília, DF, 10 jan. 2001. FORMENTI, Lígia; PALHARES, Isabela. MEC avaliará qualidade de creche e pré-escola a partir de 2019. Disponível em: $<$ https://educacao.estadao.com.br/noticias/geral,saeb-vai-avaliareducacao-infantil-e-incluira-avaliacoes-de-ciencias-para-9ano,70002374322>. Acesso em: 20 set. 2019.

FRANÇA, Luísa. Saeb: Sistema de Avaliação da Educação Básica. Disponível em: <https://www.somospar.com.br/saeb/>. Acesso em: 12 set. 2019. 
FREITAS, Eduardo. A qualidade da Educação Brasileira. Disponível em: <https://educador.brasilescola.uol.com.br/trabalhodocente/a-qualidade-educacao-brasileira.htm>. Acesso em: 17 set. 2019.

INEP Instituto Nacional de Estudos e Pesquisas Educacionais Anísio Teixeira. SAEB, 2017. Disponível em: http://portal.inep.gov.br/web/ guest/educacao-basica/saeb. Acesso em: 17 out. 2019.

INSTITUTO UNIBANCO. Como utilizar as avaliações externas para melhorar a aprendizagem. Aprendizagem em Foco, no 8, abr. 2016. Disponível em: $<$ http://www.institutounibanco.org.br/aprendizagemem-foco/8/> Acesso: 27 ago. 2019.

MACHADO, Cristiane. Avaliação externa e gestão escolar: reflexões sobre usos dos resultados. Revista@mbienteeducação, São Paulo, jan/jun. 2012. Disponível em: <http://docplayer.com.br/6277235Avaliacao-externa-e-gestao-escolar-reflexoessobre-usos-dosresultados.html >. Acesso em: 05 set. 2019.

MARQUES, Maria Vanderli de Souza. Apropriação de resultados da avaliação em larga escala em uma escola mineira de Ensino Médio: limites e possibilidades de ações gestoras. Dissertação (Mestrado Profissional). 2017. Universidade Federal de Juiz de Fora. MATEUS, Ionah Beatriz Beraldo. Didática. Maringá/PR: UniCesumar, 2014.

NOVA ESCOLA. Avaliação Externa: como compreender e utilizar os resultados. Disponível em: $<$ https://novaescola.org.br/avaliacaoexterna-compreender-e-utilizar-resultados/>. Acesso em: 13 set. 2019.

OLIVEIRA, Lina Kátia Mesquita (Coord.). Guia de Elaboração de itens: Matemática. Juiz de Fora: CAED, 2008. Disponível em: $<$ http://www.portalavaliacao.caedufjf.net/wp-content/uploads/2012/0 2/Guia_De_- Elabora\%C3\%A7\%C3\%A3o_De_Itens_MT.pdf $>$. Acesso em: 05 set. 2019.

PONTES, Luís Antônio Forjado. Indicadores educacionais no Brasil e no mundo: as diversas faces da educação. In: David, M. V. et al.. (Org.). Avaliação e indicadores educacionais - Políticas públicas e escola. $1^{\circ}$ ed. Juiz de Fora: Editora UFJF, 2012, v. 2, p. 65-85. 
SANTOS, Josiane Cristina dos. A (contra) reforma da educação pública em Minas Gerais: O programa de Avaliação da Rede Pública de Educação Básica em análise. Dissertação mestrado, 2010, 172 p. Universidade Federal de Juiz de Fora.

SANTOS, Vanice dos; CANDELORO, Rosana J. Trabalhos acadêmicos:uma orientação para a pesquisa e normas técnicas, Porto Alegre: AGE, 2006.

SIMAVE. Revista da Avaliação, 2016. Disponível em: $<$ http://www.simave.caedufjf.net/revista/>. Acesso em: 21 out. 2019. TODOS PELA EDUCAÇÃO. Quais as avaliações brasileiras e por que elas são importantes? Disponível em:

$<$ https://www.todospelaeducacao.org.br/conteudo/uais-sao-as-

avaliacoes-brasileiras-e-porque-elas-sao-importantes $>$. Acesso em: 17set. 2019.

TOKARNIA, Mariana. MEC terá novo sistema de exames e passará a avaliar creche em 2019. Disponível em: < 